\title{
Effect of chelating agents on the growth, surface polypeptide synthesis and interaction of Streptococcus agalactiae with human epithelial cells
}

\author{
MICHELLE HANTHEQUESTE BITTENCOURT DOS SANTOS ${ }^{1}$, ANDRÉIA FERREIRA EDUARDO DA COSTA ${ }^{1}$, \\ GABRIELA DA SILVA SANTOS ${ }^{1}$, ANDRÉ LUIS SOUZA DOS SANTOS ${ }^{2}$ and PRESCILLA EMY NAGAO ${ }^{1}$ \\ ${ }^{1}$ Departamento de Biologia Celular, Instituto Biologia Roberto Alcântara Gomes (IBRAG), Universidade do \\ Estado do Rio de Janeiro (UERJ), 20550-013 Rio de Janeiro, RJ; ${ }^{2}$ Departamento de Microbiologia Geral, \\ Instituto de Microbiologia Prof. Paulo de Góes (IMPPG), Centro de Ciências da Saúde (CCS), \\ Bloco E-subsolo, Universidade Federal do Rio de Janeiro (UFRJ), 21941-902 Rio de Janeiro, RJ, Brazil
}

Received September 25, 2008; Accepted October 7, 2008

DOI: 10.3892/mmr_00000065

\begin{abstract}
In the present study, the influence of the chelating agents of ethylenediaminetetraacetic acid (EDTA), ethylene glycol-bis (ß-aminoethyl ether) (EGTA) and 1,10-phenanthroline (PHEN) on growth rate, cytoadherence ability and surface protein expression was examined in a clinical strain of Streptococcus agalactiae isolated from a blood sample. EDTA and EGTA at $10 \mathrm{mM}$ did not inhibit the growth of S. agalactiae, while PHEN significantly arrested bacterial proliferation in a concentration range of $10-0.01 \mathrm{mM}$. The in vitro interaction between $S$. agalactiae and A549 cells was a time-dependent process; adherence and bacterial intracellular viability were more pronounced after $3 \mathrm{~h}$ of contact. The pre-treatment of bacterial cells with EDTA adversely influenced the adhesive properties of $S$. agalactiae to A549 cells after 2 and $3 \mathrm{~h}$, whereas EGTA only blocked this process after $3 \mathrm{~h}$. Viable intracellular bacteria were just detected after $3 \mathrm{~h}$ of interaction, and EDTA and EGTA inhibited intracellular viability in a similar fashion. Conversely, PHEN inhibited neither the adherence nor the intracellular viability of the microorganism. Furthermore, EDTA robustly suppressed surface polypeptide synthesis, suggesting a decline in the possible bacterial ligands responsible for $S$. agalactiae adhesive properties.
\end{abstract}

\section{Introduction}

Streptococcus agalactiae, known as group B Streptococcus (GBS), is the major cause of bacterial sepsis, pneumonia and

Correspondence to: Dr Prescilla Emy Nagao, Departamento de Biologia Celular, Instituto Biologia Roberto Alcântara Gomes (IBRAG), Universidade do Estado do Rio de Janeiro (UERJ), Rua São Francisco Xavier, 524-PHLC $/ 2^{\circ}$ andar, Maracanã, 20550-013 Rio de Janeiro, RJ, Brazil

E-mail:pnagao@uol.com.br

Key words: Streptococcus agalactiae, chelating agents, growth, cytoadherence, surface polypeptides meningitis in neonates and has emerged as an increasingly common cause of invasive disease in immunocompromized individuals (1). About $50 \%$ of infants born to infected women became colonized with $S$. agalactiae during delivery and $1 \%$ of the colonized infants develope severe GBS infection. The main route of neonatal infection is the ascending spread of S. agalactiae into the amniotic fluid followed by the aspiration of contaminated amniotic fluid by the fetus. The bacteria can then colonize and infect the lungs, resulting in pneumonia. Subsequent transmigration of $S$. agalactiae across the epithelial border allows the bacteria to invade the bloodstream and eventually reach the meninges (1). The adherence of $S$. agalactiae to the epithelial cells of the mother (intestinal and vaginal) and infant (lung) may be essential for virulence $(2,3)$.

Metal-chelating agents are able to selectively disturb the essential metal metabolism of cells, interfering with metal acquisition and bioavailability for crucial reactions. Chelating agents are also inhibitors of several bacterial adhesins $(4,5)$; for instance, ethylenediaminetetraacetic acid (EDTA) is capable of inhibiting adhesion molecules of divergent specificities from members of the genera Actinomyces, Capnocytophaga, Fusobacterium, Porphyromonas and Prevotella. Some of the adhesins are lectins capable of binding carbohydrates, whereas others are specific for proteins and/or hydrophobins (6). The metal chelator EDTA is known to have activity against biofilms of gram-positive bacteria such as Staphylococcus aureus. EDTA can also kill planktonic cells of Pseudomonas aeruginosa and causes a rapid dispersion of microorganisms, suggesting that magnesium, calcium and iron are involved in $P$. aeruginosa biofilm maintenance (7). In addition, these chelating compounds may inhibit the hydrolytic activity of different types of metal-dependent enzymes, such as metallo-type proteases. We recently demonstrated that clinical strains of $S$. agalactiae secrete metalloproteases into the extracellular environment. These $S$. agalactiae metallopeptidases were able to cleave several key host proteins, such as fibronectin, laminin, type IV collagen, fibrinogen and albumin, suggesting a possible participation during bacterial tissue dissemination. Chelating agents robustly inhibited the metalloprotease activities released 
by $S$. agalactiae, resulting in the blockage of the hydrolysis of these proteinaceous substrates (8).

In the present study, we aimed to investigate the effect of chelating agents such as EDTA, ethylene glycol-bis ( $ß$-aminoethyl ether) (EGTA) and 1,10-phenanthroline (PHEN) on the growth rate of a clinical sample (designated 90186 strain) belonging to the serotype V of $S$. agalactiae, which was isolated from blood of an adult patient. Interaction assays were performed to examine the influence of the metal-chelating compounds on interaction with lung epithelial cells, and the effect of the chelating agents on surface protein expression was also analyzed.

\section{Materials and methods}

Chemicals. Brain heart infusion medium (BHI) was obtained from Difco Laboratories (Detroit, MI, USA). Blood agar base (BAB) was purchased from Oxoid (Basingstoke, Hampshire, England). The chelating agents PHEN, EDTA and EGTA, M199 medium, collagenase IV, all antibiotics and dimethylsulfoxide (DMSO) were obtained from Sigma Chemical Co. (St. Louis, MO, USA). Fetal calf serum (FCS) and Dulbecco's modified Eagle's medium (DMEM) were purchased from Gibco BRL (Gaithersburg, MD, USA). The other reagents were of analytical grade.

Bacterial strain and growth conditions. The S. agalactiae 90186 strain (serotype V), partially investigated for its adhesive properties (9), was used throughout this study. The strain was obtained from the Culture Collection of the Laboratório de Cocos Patogênicos (Departamento de Microbiologia Médica, Instituto de Microbiologia Prof. Paulo de Góes, Universidade Federal do Rio de Janeiro, Brazil), identified as $S$. agalactiae and serotyped as previously described (10). Microorganisms were stored after lyophilization and recovered in BHI broth. The $S$. agalactiae strain was grown in Erlenmeyer flasks containing $200 \mathrm{ml}$ of M199 medium for $16-18 \mathrm{~h}$ at $37^{\circ} \mathrm{C}$.

Effect of chelating agents on S. agalactiae growth. Experiments were performed in 10x100-mm glass tubes containing $1 \mathrm{ml}$ of M199 medium. The inoculum consisted of $10 \%$ of a 6 h culture of $S$. agalactiae (isolated 90186-blood) containing $\sim 2.0 \times 10^{8}$ cells. EDTA and EGTA were dissolved in water at $100 \mathrm{mM}$, while PHEN was dissolved in DMSO at $100 \mathrm{mM}$. All drugs were filter-sterilized. The bacteria were incubated at $37^{\circ} \mathrm{C}$ for $1 \mathrm{~h}$ in the absence or presence of the chelating agents at different concentrations $(10,1.0,0.1,0.01$ and $0.001 \mathrm{mM})$. Cell growth was estimated by plating and counting the resulting colonies, which manifested in $\mathrm{BAB}$ plates containing 5\% sheep-desfibrinated blood. Untreated and DMSO-treated $S$. agalactiae cultures were followed concomitantly as controls (8).

Epithelial cell culture. A549 is a human type II alveolar epithelial-like lineage derived from the lung carcinomatous tissue of human patients, and is widely used as a model for respiratory pathogen infection. The cultures were maintained and grown to confluence at $37^{\circ} \mathrm{C}$ in $25-\mathrm{cm}^{2}$ culture flasks containing DMEM supplemented with $10 \%$ FCS in a $5 \% \mathrm{CO}_{2}$ atmosphere.

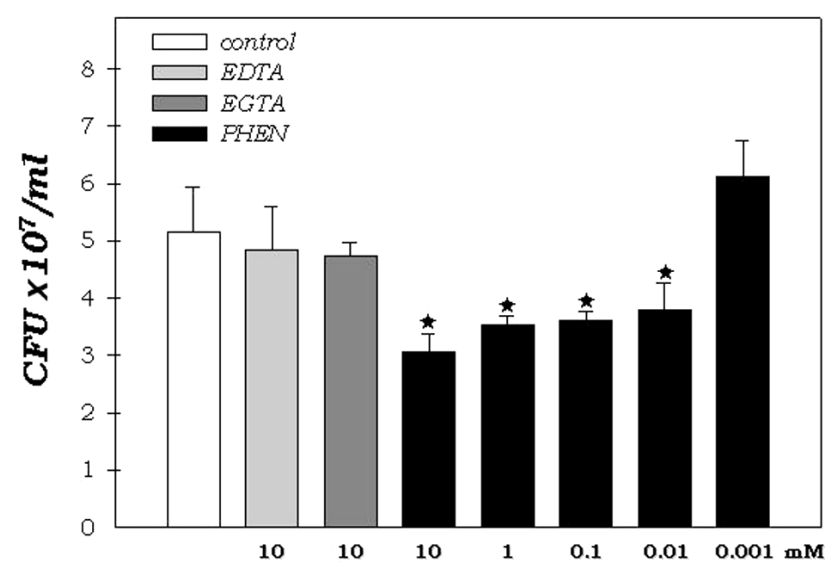

Figure 1. Effect of chelating agents on the growth of S. agalactiae (90186blood strain). After growth in M199 medium, bacterial cells were pre-treated for $1 \mathrm{~h}$ in the absence (control) or presence of EDTA (10 mM), EGTA $(10 \mathrm{mM})$ or PHEN $(10,1.0,0.1,0.01$ and $0.001 \mathrm{mM})$. Cells were harvested, washed with PBS and inoculated in fresh solid medium to measure the colony-forming units. Values represent the means \pm standard error of three independent experiments, performed in triplicate. GBS cells treated with chelating agents that had a growth rate significantly different from the controls are shown $\left({ }^{\star} \mathrm{P}<0.05\right.$, Student's t-test $)$.

Bacterial binding and intracellular viability assays. Confluent cultures of A549 cells were allowed to interact with $S$. agalactiae $\left[5 \times 10^{7}\right.$ colony-foming units $\left.(\mathrm{CFU})\right]$ treated or untreated for $1 \mathrm{~h}$ with $10 \mathrm{mM}$ EDTA, $10 \mathrm{mM}$ EGTA or $0.001 \mathrm{mM}$ PHEN. For the bacterial binding assays, infected monolayers were rinsed three times with M199 then lysed in a $0.5-\mathrm{ml}$ solution of $25 \mathrm{mM}$ Tris, $5 \mathrm{mM}$ EDTA, $150 \mathrm{mM} \mathrm{NaCl}$ and $1 \%$ Igepal. The viability of total bacteria (intracellular plus surface adherent) was estimated by plating epithelial lysates and counting the resulting colonies emerging in BAB plates containing 5\% sheep-desfibrinated blood. To measure bacterial internalization, the infected monolayers were incubated for $1 \mathrm{~h}$, rinsed three times with M199 medium and incubated for an additional 2-h period in M199 containing bactericidal amounts of gentamicin $(100 \mu \mathrm{g} / \mathrm{ml})$ and penicillin $\mathrm{G}(5 \mu \mathrm{g} / \mathrm{ml})$. The number of internalized bacteria was determined as outlined above. Adherence rates were determined as: [CFU of total cell-associated (intracellular viable plus surface adherent) GBS-CFU intracellular GBS] (9).

Biotinylated S. agalactiae extract preparation. Biotinylated bacterial extracts were prepared using a commercial kit (Amersham-Pharmacia, UK). Briefly, S. agalactiae treated or untreated for $1 \mathrm{~h}$ with $10 \mathrm{mM}$ EDTA, $10 \mathrm{mM}$ EGTA or $0.001 \mathrm{mM}$ PHEN was washed twice with cold PBS and incubated with $40 \mathrm{mM}$ sodium bicarbonate buffer $\mathrm{pH} 8.6$ (250 $\mu \mathrm{l} /$ well) containing $150 \mathrm{mM} \mathrm{NaCl}$ and $2 \mu 1$ of biotin reagent, according to the supplier's instructions. Cells were incubated for $30 \mathrm{~min}$ at $4^{\circ} \mathrm{C}$ under gentle agitation. After a washing step with PBS, cellular integrity was monitored by optical microscopy observation. Cell extracts were obtained by adding $200 \mu \mathrm{l} /$ well of lysis buffer $(25 \mathrm{mM}$ Tris- $\mathrm{HCl} \mathrm{pH} 7.5$ containing $250 \mathrm{mM} \mathrm{NaCl}, 5 \mathrm{mM}$ EDTA, 1\% Igepal CA-630, $1 \mathrm{mM}$ phenylmethylsulfonyl fluoride and $40 \mu \mathrm{M}$ leupeptin) for $30 \mathrm{~min}$ at $4^{\circ} \mathrm{C}$. Following the centrifugation of cell extracts at $6000 \mathrm{~g}$ for $15 \mathrm{~min}$ at $4^{\circ} \mathrm{C}$, the supernatants were subjected to electrophoresis in $10 \%$ polyacrylamide separating gel (SDS- 


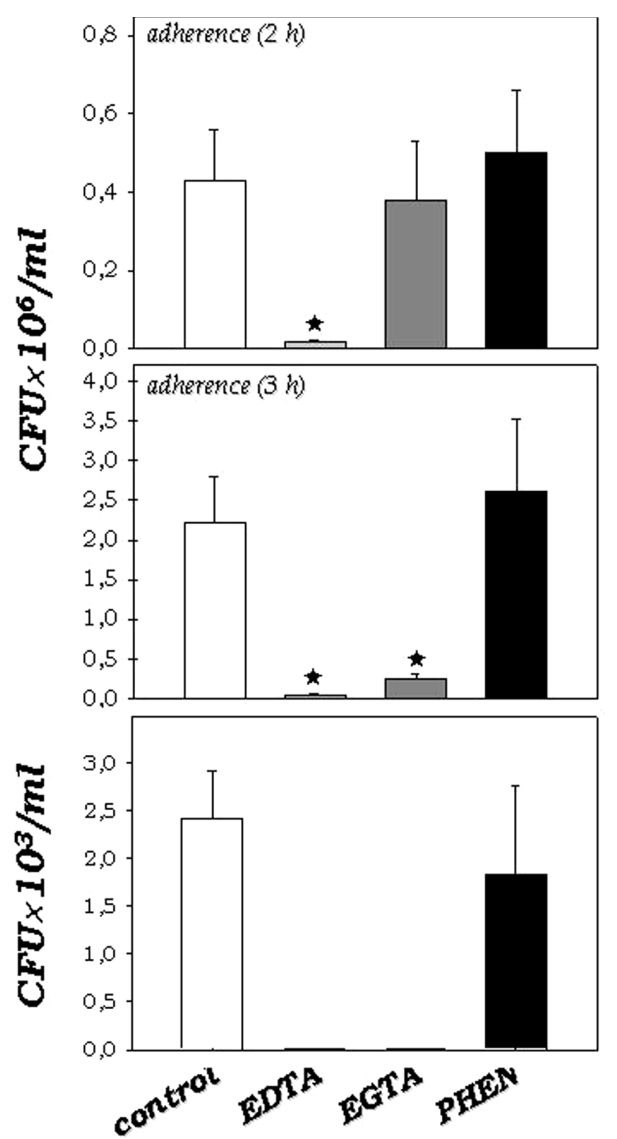

Figure 2. Interaction of S. agalactiae (90186-blood strain) with A549 epithelial cell lineage. Confluent cultures were allowed to interact with $S$. agalactiae cells pre- or untreated for $1 \mathrm{~h}$ with $10 \mathrm{mM}$ EDTA, $10 \mathrm{mM}$ EGTA or $0.001 \mathrm{mM}$ PHEN. Adhered bacteria and intracellular viability were calculated as described in Materials and methods. Each value is the mean \pm SEM of four samples. Systems treated with chelating agents that had an interaction rate significantly different from the controls are shown ( ${ }^{\star} \mathrm{P}<0.05$, Student's t-test).

PAGE) under non-reducing conditions (11). Fractionated samples were transferred to Immobilon-P membranes (Amicon) using the Bio-Rad mini-gel electrophoresis system. Nonspecific sites of the membranes were blocked with 3\% BSA in PBS overnight at $4^{\circ} \mathrm{C}$. The membranes were incubated with horse-radish peroxidase-conjugated streptavidin (1:1500). Bound complexes were detected using the enhanced chemiluminescence system (ECL, Amersham-Pharmacia, UK).

Statistical analysis. The experiments were repeated at least three times, and conditions were performed in triplicate. Representative images of these experiments are shown. Statistical analysis of the data was performed using the Student's t-test, version EPI-INFO 6.04 (database and statistics program for public health) computer software. $\mathrm{P} \leq 0.05$ was considered statistically significant.

\section{Results and Discussion}

Chelating agents have a broad variety of reactions in biological systems. EDTA has traditionally been considered a potentiator of antimicrobial activity against gram-negative bacteria (7). However, very little interactive effect was observed between chelating agents against gram-positive bacteria. Our results show that EDTA and EGTA at $10 \mathrm{mM}$ did not inhibit

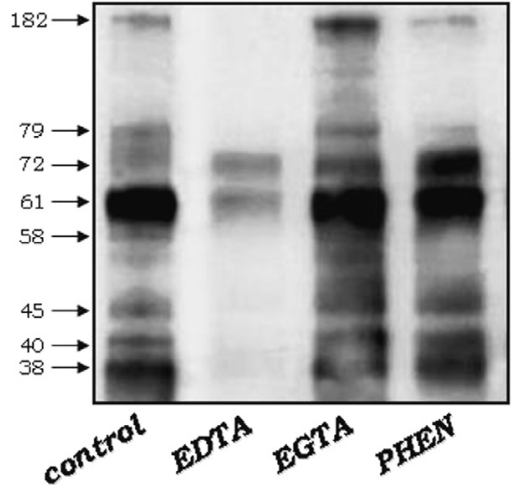

Figure 3. Modulation of S. agalactiae (90186-blood strain) surfacebiotinylated proteins by chelating agents. $S$. agalactiae cells pre- or untreated for $1 \mathrm{~h}$ with $10 \mathrm{mM}$ EDTA, $10 \mathrm{mM}$ EGTA and $0.001 \mathrm{mM}$ PHEN were biotinylated using a commercial kit (Amersham-Pharmacia, UK). Bacterial surface-bound proteins were extracted using lysis buffer and resolved in nonreducing conditions on a $10 \%$ polyacrylamide separating gel. After being transferred to PVDF membranes, proteins were probed with a streptavinperoxidase conjugate and revealed using a chemiluminescence reagent. Notably, bacterial cells treated with EDTA showed a drastic inhibition in surface protein expression as compared to the control cells. The numbers represent the molecular masses of the standard proteins, expressed in $\mathrm{kDa}$.

S. agalactiae proliferation in vitro. However, PHEN at this concentration promoted a significant decrease of $\sim 42 \%$ in bacterial growth (Fig. 1), and effectively inhibited S. agalactiae growth at up to $0.01 \mathrm{mM}$ (Fig. 1). The mechanism by which this specific chelating agent acts is not fully understood, but is generally attributed to its ability as a chelator. Thus, essential divalent cations, such as magnesium, calcium, iron and particularly zinc ions, remain unavailable in the presence of PHEN, inhibiting S. agalactiae development and maintenance. Recently, Reidmiller et al (12) described the antimicrobial properties of the chelating agent EDTA on streptococcal bovine mastitis isolates. However, this inhibitory phenomenon was observed only when EDTA was used at higher concentrations of 30-100 mM.

The adherence of $S$. agalactiae to epithelial cells is required for the colonization of the rectal and vaginal tracts of the mother and for persistence in the lungs of the neonate. We demonstrated that $S$. agalactiae cells adhered to and were ingested by A549 cells. The interaction process between $S$. agalactiae and A549 cells was a time-dependent phenomenon in which adherence and bacterial intracellular viability were more pronounced after $3 \mathrm{~h}$ of bacteria-mammalian cell contact (Fig. 2). The pre-treatment of bacterial cells for $1 \mathrm{~h}$ with EDTA at $10 \mathrm{mM}$ negatively influenced the adhesive properties of $S$. agalactiae to A549 cells after 2 and $3 \mathrm{~h}$, whereas EGTA $(10 \mathrm{mM})$ only blocked this process after $3 \mathrm{~h}$. Viable intracellular bacteria were just detected after $3 \mathrm{~h}$ of interaction, and EDTA and EGTA robustly inhibited intracellular viability in a similar fashion. In contrast, PHEN at $0.001 \mathrm{mM}$ inhibited neither the adherence nor the intracellular viability of S. agalactiae with A549 cells (Fig. 2). The finding that metal-binding agents such as EDTA and EGTA inhibit the adherence and invasion of $S$. agalactiae cells suggests that these chelators bind to essential ion(s) for their adhesive properties. In this context, EDTA and EGTA are able to form a powerful complex with $\mathrm{Ca}^{2+}$; this multi-functional divalent cation has been implicated in a large number of biological 
processes in eukaryotic and prokaryotic cells $(13,14)$. In bacteria, $\mathrm{Ca}^{2+}$ is implicated in processes as important and diverse as cell cycle and division, competence, pathogenesis, motility, and chemotaxis and quorum sensing (4).

S. agalactiae express specific surface proteins which mediate interactions with the components of the host extracellular matrix and host surface components, triggering the adherence, colonization and/or invasion of host cells and tissues as well as host defence evasion. The availability of the whole genome sequence of the human pathogen $S$. agalactiae has provided insights into the repertoire of the cell surface proteins present in this bacterial species. Thirty-five cell wallassociated proteins that may play a role in the adhesion, invasion, inhibition of phagocytosis and evasion of host immune defence mechanisms have been annotated $(15,16)$. As is well known, chelating agents repress the synthesis of surface receptor in several biological systems $(13,17)$, disturbing the physical contact between microorganisms and host cells. Our results show that EDTA vigorously suppressed the synthesis of several surface polypeptides in comparison with the control cells (Fig. 3). Of note, pre-treatment with EGTA and PHEN stimulated the expression of certain surface polypeptides, for instance the 182,79 and $72 \mathrm{kDa}$ molecules observed in EGTA-treated cells and the $72 \mathrm{kDa}$ polypeptide in PHENtreated ones (Fig. 3). Chelating agents are clearly inhibitors of several bacterial surface polypeptides that act as adhesins. In this sense, the Fim $\mathrm{H}$ adhesin of Escherichia coli was sensitive to EDTA (5). Lü-Lü et al (17) noted that the glucan-binding lectin of Streptococcus sobrinus is also inhibited by chelating agents. EDTA powerfully repressed the expression of several surface polypeptides in $S$. agalactiae. These results may partially explain the drastic inability of $S$. agalactiae cells to bind to A549 cells in vitro. Conversely, EGTA- and PHENtreated S. agalactiae cells displayed analogous surface polypeptide profiles as compared to non-treated cells. Nevertheless, EGTA was capable of inhibiting the adhesion and intracellular viability of $S$. agalactiae after $3 \mathrm{~h}$ of interaction with A549 cells. Thus, EGTA probably operates by inhibiting the interaction process using a dissimilar mechanism from that of EDTA. In a previous report by our research group, we observed that EGTA fully inhibited hydrolytic surface activities and released metallo-type proteases produced by the S. agalactiae 90186 strain (8). Proteases play several roles during different phases of bacteria-host cell interplay, including the cleavage of host surface receptors, and/or act as an adhesive molecule (18). Based on these findings, we cannot discount the hypothesis that EGTA inhibits $S$. agalactiaeA549 interaction by directly acting on the metalloproteases produced by this bacterial pathogen.

In summary, our results show that $S$. agalactiae efficiently adhere to human epithelial lung cells in vitro. We demonstrated that $S$. agalactiae is able to invade A549 cells, possibly remaining viable for several hours inside the endocytic vacuoles without causing any significant damage to the host cells (data not shown). Knowledge of the specific receptors responsible for the interaction between epithelial cells and $S$. agalactiae and the modulation of host tissues by metalchelating agents may be essential to understanding the hematogenous routes of infection employed by this opportunistic pathogen.

\section{Acknowledgements}

This work was supported by grants from CNPq, CAPES, FAPERJ, FUJB and SR-2/UERJ. We are also grateful to Mariléa Temperini and Vanessa Figueiredo Albino for laboratory assistance.

\section{References}

1. Nizet V, Ferrieri P and Rubens CE: Molecular pathogenesis of group B streptococcal disease in newborns. In: Streptococcal Infections: Clinical Aspects, Microbiology, and Molecular Pathogenesis. Stevens DL, Kaplan EL (eds). Oxford University Press, New York, pp180-221, 2000.

2. Gutenkunst H, Eikmanns BJ and Reinscheid DJ: The novel fibrinogen binding protein FbsB promotes Streptococcus agalactiae invasion into epithelial cells. Infect Immun 72: 3495-3504, 2004

3. Rubens CE, Smith S, Hulse M, Chi E and van Belle G: Respiratory epithelial cell invasion by group B streptococci. Infect Immun 60: 5157-5163, 1992.

4. Michiels J, Xi C, Verhaert J and Vanderleyden J: The functions of $\mathrm{Ca}^{2}$ in bacteria: a role for EF-hand proteins? Trends Microbiol 10: 87-93, 2002.

5. Taweechaisupapong $\mathrm{S}$ and Doyle RJ: Sensitivity of bacterial coaggregation to chelating agents. FEMS Immunol Med Microbiol 28: 343-346, 2000.

6. Sharon $\mathrm{N}$ and Lis $\mathrm{H}$ : Lectins as cell recognition molecules. Science 246: 227-234, 1989.

7. Banin M, Brady KM and Greenberg EP: Chelator-induced dispersal and killing of Pseudomonas aeruginosa cells in a biofilm. Appl Environ Microbiol 72: 2064-2069, 2006.

8. Soares GCMT, Silva BA, Santos MHB, Santos ALS, Morandi VM and Nagao PE: Metallopeptidases produced by group B Streptococcus: Influence of proteolytic inhibitors on growth and on interaction with endothelial cell lineage. Int J Mol Med 22: 119-126, 2008.

9. São Jose AS, Miyazaki NHT, Hirata R Jr, Mattos-Guaraldi AL and Nagao PE: Intracellular viability in human non-polarized respiratory epithelial $16 \mathrm{HBE}$ 140- cells by group B Streptococcus serotype III clinical isolates presenting $162-\mathrm{kb}$ and $183-\mathrm{kb}$ virulence markers. Int J Mol Med 17: 533-538, 2006.

10. Lancefield RC: A serological differentiation of specific types of bovine hemolytic streptococci (group B). J Exp Med 59: 441-458, 1934.

11. Figueiredo CC, Lima OC, Carvalho L, Bezerra LL and Morandi V: The in vitro interaction of Sporothrix schenckii with human endothelial cells is modulated by cytokines and involves endothelial surface molecules. Microb Pathog 36: 177-188, 2004.

12. Reidmiller JS, Smith WL, Sawyer MM, Osburn BI, Stott JL and Cullor JS: Antimicrobial properties of the chelating agent EDTA on Streptococcal bovine mastitis isolates. J Food Prot 69: 1460-1462, 2006

13. Branen JK and Davidson PM: Enhancement of nisin, lysozyme, and monolaurin antimicrobial activities by ethylenediaminetetraacetic acid and lactoferrin. Int J Food Microbiol 90: 63-74, 2004.

14. Ofek I and Doyle RJ: Bacterial Adhesion to Cells and Tissues. Chapman and Hall, New York, 1994.

15. Lindahl G, Stalhammar-Carlemalmb M and Areschoug T: Surface proteins of Streptococcus agalactiae and related proteins in other bacterial pathogens. Clin Microbiol Rev 18: 102-127, 2005.

16. Tettelin H, Masignani V, Cieslewicz MJ, Eisen JA, Peterson S, Wessels MR, Paulsen IT, Nelson KE, Margarit I, Read TD, Madoff LC, Wolf AM, Beanan MJ, Brinkac LM, Daugherty SC, DeBoy RT, Durkin AS, Kolonay JF, Madupu R, Lewis MR, Radune D, Fedorova NB, Scanlan D, Khouri H, Mulligan S, Carty HA, Cline RT, Van Aken SE, Gill J, Scarselli M, Mora M, Iacobini ET, Brettoni C, Galli G, Marini M, Vegni F, Maione D, Rinaudo D, Rappuoli R, Telford JL, Kasper DL, Grnadi G and Fraser CM: Genome analysis of multiple pathogenic isolates of Streptococcus agalactiae: Implications for the microbial 'pangenome'. Proc Natl Acad Sci USA 102: 13950-13955, 2005.

17. Lü-Lü, Singh JS, Galperin MY, Drake D, Taylor KG and Doyle RJ: Chelating agents inhibit activity and prevent expression of streptococcal glucan-binding lectins. Infect Immun 60: 3807-3813, 1992.

18. Sedo A, Mandys V and Krepela E: Cell membrane-bound proteases: not 'only' proteolysis. Physiol Res 45:169-176, 1996. 